\title{
Entre a atividade política e a ação policial: sobre a institucionalização das relações que envolvem a educação e 0 meio ambiente
}

Rodrigo Barchi*

http://dx.doi.org/10.1590/0103-7307201407512

“O pensamento é como o Vampiro, não tem imagem,

nem para constituir modelo, nem para fazer cópias".

(Deleuze e Guattari)

\section{Resumo}

Esse artigo busca discutir a institucionalização das perspectivas teóricas e práticas da educação ambiental, tendo como objetivo questionar se esse processo pode manter o potencial político da educação ambiental, ou se ele será responsável por * Universidade de Sorocaba (UNISO), Sorocaba, SP, Brasil. rodrigo.barchi@prof.uniso.br sua despolitização, por transformá-la em instrumento de manutenção do poder governamental constituído, com a justificativa de ser a responsável pela salvação da espécie humana e de outros seres vivos da catástrofe ecológica que se aproxima. Para esse debate, serão utilizadas principalmente as noções de política, polícia, consenso e dissenso no trabalho de Jacques Rancière, além da ideia de grande saúde na perspectiva de Nietzsche, e das forças molares e moleculares desenvolvidas por Felix Guattari.

\section{Palavras-chave}

Política, educação, meio ambiente. 


\title{
Between political activity and police action: a debate on the institutionalization of the relations that encompass education and environment
}

\begin{abstract}
This article discusses if the institutionalization process of theoretical and practical perspectives on environmental education will maintain the political potential of this pedagogical proposal or if it can destroy this force The discussion examines the definitions of 'politics', 'the police', 'consensus' and 'dissensus' in the work of Jacques Rancière, alongside the concepts of 'great health' presented by Nietzche, and 'molar' and 'molecular' forces by Felix Guattari.
\end{abstract}

Keywords

Politics, education, environment. 


\section{Introdução}

A educação ambiental pode ser considerada uma das principais herdeiras dos movimentos ecologistas que há quase meio século chegaram a contestar, diversas vezes, a existência do Estado e do capital, em suas reivindicações por mudanças radicais nas relações entre os seres humanos e o ambiente planetário. Ela ganhou pertinência e relevância nos debates tanto sobre meio ambiente quanto sobre educação, e grandes mobilizações foram realizadas para torná-la foco de ação estatal. No Brasil, tornou-se uma política pública entre o fim dos anos 1990 e o começo da década passada (Brasil, 1999, 2002), promovendo, nos anos seguintes, a criação de diversos órgãos e documentos para instrumentalizar e regular suas ações.

Este trabalho busca debater a institucionalização da educação ambiental como uma política pública, a partir do questionamento sobre o quanto esse processo pode ou não manter a força política dessa proposta pedagógica e/ou transformá-la somente em mais uma ferramenta de manutenção do poder governamental instituído, sob a égide de um dispositivo que pode salvar os seres humanos e o planeta de sua autodestruição. Para tanto, serão utilizadas as contribuições das noções de polícia e política, de consenso e dissenso no trabalho de Jacques Rancière, e de algumas ressonâncias de Nietzsche e Guattari sobre instituições identitárias e forças molares e moleculares.

A discussão aqui proposta se baseia e se justifica a partir do alerta feito por alguns pensadores ${ }^{1}$ sobre o quanto a educação ambiental, ao ser institucionalizada, pode estar correndo o risco de se transformar, mais do que em banalidade educacional, em uma doutrina pedagógica cristalizada e imutável, instauradora de ações policiais e de práticas pedagógicas reguladoras de condutas, de tal forma que faz com que essa perspectiva pedagógica perca sua força política, herdada dos movimentos políticos e sociais, capaz de promover mudanças nas relações entre os humanos e os ambientes terrestres.

\section{Sobre as pequenas e as grandes políticas: micropolíticas e macropolíticas}

Escreveu Nietzsche (2012) em Schopenhauer educador que vivemos em um período de átomos, de caos de átomos. Essa afirmação, mais esperançosa e filosoficamente militante do que apocalíp-
1. Alguns dos muitos debates realizados sobre a cristalização, institucionalização e sedentarização da Ecologia e da Educação Ambiental podem ser encontrados nos trabalhos de: Alves (2010), Correa (2012), Godoy (2008), Guimarães (2007), Passetti (2007), Preve et al. (2012) Preve e Correia (2007) e Reigota (2008). 
tica, acreditava que, após a liberação das forças antagônicas egoístas que estavam presas pela instituição religiosa na Idade Média, uma série de indicadores mostrava que a terra estava coberta pelas forças do egoísmo das classes possuidoras e do despotismo militar. Mesmo com os esforços desse último, para tomar o Estado e tentar transformá-lo no ídolo que um dia foi a instituição católica, Nietzsche acreditava que um desmoronamento generalizado ocorreria, e que a revolução atômica seria irreversível. Afinal de contas, os Estados se opunham e se dilaceravam, as ciências constantemente massacravam as crenças que eram cristalizadas, e os meios intelectuais não eram mais do que refúgios no interior desse intenso turbilhão.

A reivindicação pela liberação dos humanos de sua posição de submissão ao Estado, como objetivo e destino supremo da humanidade - assim como a submissão à história, à raça e à ciência - se mostram, em Nietzsche, como uma fuga da loucura coletiva, a qual constantemente leva os humanos rumo a uma barbárie generalizada guiada pelo amor e pelo medo em uma frágil ideia identitária que se quer imóvel e eterna, impossibilitando o exercício de um pensamento que não esteja intrínseco à noção da existência humana, vinculada diretamente à existência da pátria e de tudo que foi criado ao redor dela.

O medo humano de pensar fora das instituições identitárias, unificantes e totalizantes, que permeiam o pensamento e as práticas políticas, científicas e artísticas, ocorre por causa da distância que os humanos buscam em se manter do que é ser um animal. A vida animal, dividida entre a fome e o desejo, desprovida de sentido e de qualquer ambição superior, para Nietzsche, só assume um sentido quando a natureza inteira se acerca do humano e nele se faz entender a si mesma, abandonando sua animalidade.

Para essa tarefa, é necessário, desde cedo, “conceder o coração” ao Estado, ao lucro, à vida mundana, à ciência, justamente para esquivar-se da tarefa de dedicação a si mesmo. É preciso escapar da animalidade presente em cada um de nós, humanos, inserindo-nos no barulho da vida cotidiana, a qual nos impede de aprofundar demais - além do que se diz na religião, no pensamento institucional estatal e na ciência - na questão de como se constrói o ser humano.

Todos sabemos por experiência própria com que presteza as lembranças desagradáveis afloram às vezes na nossa consciência e o quanto nos esforçamos, através do nosso comportamento e das nossas palavras, para expulsá-las violentamente do nosso espírito - porém, a forma geral da nossa vida 
deixa perceber que nos encontramos sempre nesse estado de ânimo: o que é então essa coisa que nos assalta tão frequentemente, quem é este mosquito que não nos deixa dormir? Fantasmas giram à nossa volta, a cada momento da vida querem nos dizer algo, mas recusamos ouvir as vozes destes fantasmas. Tememos, quando estamos sós e silenciosos, que algo nos seja murmurado no ouvido, e é por isso que detestamos o silêncio e nos aturdimos com a vida em sociedade (Nietzsche, 2007, p. 65).

Além do barulho, há a pressa da vida cotidiana, que além de não nos permitir ler e escrever de maneira meticulosa e dedicada - "um trabalho de ourives", dizia Nietzsche (2004) em Aurora - também não permite que se desenvolvam nos humanos, apressados e barulhentos, as qualidades e os sentidos necessários para essa imersão sobre si mesmos. Do mesmo jeito que os leitores modernos não têm tempo de ler as entrelinhas e os significados embutidos em cada palavra e frase dos livros - e consequentemente, os textos também são escritos de maneira apressada - a entrega da vida ao Estado, à ciência, à religião, ao capital e à razão esvai totalmente a possibilidade do afastamento necessário para que possa haver uma efetiva dedicação sobre a questão tão cara a Nietzsche: como o sujeito se constrói, como ele se torna o que é.

Mais adiante, na introdução tardia de A gaia ciência - que, de acordo com Larossa (2005), não está mais sob o signo da negação da terceira intempestiva, mas sob o signo da travessia, já que, mais do que negar as sublimidades do Estado, da raça e da ciência, buscava a experimentação singular que faria o indivíduo ser o que é -, Nietzsche se pergunta se a filosofia não passava de uma simples e má interpretação do corpo, já que toda necessidade corpórea era dissimulada sob as insanidades do que ele entendia como a metafísica - a objetividade, o ideal e a ideia, a espiritualidade - e que o valor da vida não é, para essa filosofia, mais do que sintomas de determinadas constituições físicas já que, constantemente, o Sol, o sossego, a brandura, a paciência, o repouso e o próprio remédio eram chamados para socorrer os corpos doentes em seus momentos mais críticos.

A esperança, para Nietzsche, é que aquele que ele intitulava de médico filósofo, que estudava a saúde geral do povo, da época, da raça e da humanidade, deixasse de lado seus esforços pela busca ou pela conceituação da verdade, mas que percebesse que a filosofia, ao falar de outras coisas - como a saúde, a força e a vida -, precisava deixar de lado sua constante instauração de verdades e normas, de cer- 
tos e errados, para conseguir começar a tarefa de "desdivinização" da natureza e de naturalização dos humanos com uma natureza redescoberta, liberta da noção de mundo imutável e teleológico.

Provavelmente o caos de átomos, sugerido por ele, ganhasse ainda mais força com esse médico filósofo, aquele capaz de colaborar no processo de elaboração da grande saúde afirmadora e instauradora de uma vida capaz de apresentar sentidos novos e propiciar novos significados à existência (Azeredo, 2011). Vida que somente seria possível com a destruição dos valores cristalizados e estagnados, que, por tanto tempo, haviam estabelecido normas, leis e consensos que, ao mesmo tempo, buscavam o cerceamento e a proteção dos indivíduos sob os pseudoauspícios da religião, do Estado e da ciência monolítica racionalista. Portanto, grande saúde que seria também uma grande política, de combate ao niilismo instaurador de uma moral baseada sobre valores criados a partir de seres fantasmagóricos inexistentes.

Para compreender um pouco melhor o que Nietzsche sugeria como tempo ou caos de átomos e a sua relação com a grande saúde ou grande política, é necessário recorrer ao que Felix Guattari compreendia como micropolítica e macropolítica. O pensador francês argumenta que a micropolítica analisa as formações do desejo no campo social e o seu cruzamento com as diferenças sociais mais amplas, no campo da macropolítica. Enquanto a primeira sugere uma ação molecular, a segunda sugere uma ação molar, mas não necessariamente sendo as duas contraditórias e/ou completamente opostas.

Ao usar os exemplos dos movimentos homossexuais e feministas, entre outros, para afirmar que, mesmo surgindo de miniprocessos de singularização e desejo, em grande parte dos casos, essas organizações buscam uma representatividade para se tornar aceitas pela macropolítica e conquistar seus direitos exercidos em leis e normas devidamente instituídas e defendidas pelos aparatos do Estado, caindo em um sistema de recuperação ou modelização, ou seja, de assimilação e homogeneização de um processo que outrora se afirmava como singular e autônomo:

É por isso que acredito que há um nível nos grupos autônomos (nível molar) em que eles são envolvidos por circunscrições e entram em relações de força que lhes dão uma figura de identidade. Mas a única garantia de que não transformem seus processos de singularização em bandeira (o que iria contra a própria realidade desses processos) é tentar preservar a função de autonomia. É exatamente aí que todo trabalho pode ser desenvolvido: nos 
pontos de coexistência desses " $n$ " níveis, cuja relação não obedece a uma lógica binária de falso/verdadeiro \& cia (Guattari; Rolnik, 2010, p. 153).

A dicotomização entre o molar e o molecular e a macro e a micropolítica pode trazer o risco do surgimento dos pequenos fascismos dentro dos movimentos, a partir do momento em que certos indivíduos, seduzidos pela liderança e pelo exercício de poder dentro dos grupos, passam a levar ao extremo a diferença entre o que se acredita ser o certo e o errado. Esses mesmos indivíduos, com suas palavras de ordem, passam a minimizar a participação e até a excluir aqueles que não se atrelam à perspectiva dominante nesse grupo, e acabam podendo se tornar o reflexo invertido daqueles que, até então, eram combatidos.

Ao ganhar status de aceitação perante as grandes organizações políticas e sociais características da democracia que Guattari chama de “investimentos libidinais dominantes", intrínsecas ao Capitalismo Mundial Integrado, essas reivindicações, outrora de características predominantemente moleculares, passam a se tornar parte do consenso que reproduz os mesmos valores homogeneizantes e hegemônicos que antes tentava desfazer. Se, em até certo momento, essas lutas e aspirações eram capazes de sugerir "novas atitudes, novas sensibilidades, novas práxis" (Guattari; Rolnik, 2010, p.157), capazes de impedir o retorno das velhas estruturas, ao reivindicarem primordialmente a sua inclusão nas esferas monolíticas de controle social, querem para si apenas seu lugar ao sol, recusando tudo o que um dia propusera e desejara.

\section{Consenso e dissenso: polícia e política}

Deleuze e Guattari (1997) questionaram se existe algum meio de subtrair o pensamento ao modelo do Estado. 0 que existe para esses dois pensadores franceses é a forma-Estado desenvolvida no pensamento, uma noologia, que fixaria nos indivíduos, objetivos, caminhos, condutos, canais e órgãos. O Estado, no próprio pensamento humano, ganharia uma centralidade que o tornaria universal por direito, princípio único de partilha entre os sujeitos rebeldes selvagens e os sujeitos dóceis civilizados. O Estado não é mais do que uma extensão do pensamento humano, o qual, em contrapartida, não é mais do que a forma-Estado interiorizada no pensamento:

0 Estado proporciona ao pensamento uma forma de interioridade, mas o pensamento proporciona a essa interioridade uma forma de universali- 
dade: "a finalidade da organização mundial é a satisfação dos indivíduos racionais no interior de Estados particulares livres". É uma curiosa troca que se produz entre o Estado e a razão, mas essa troca é igualmente uma proposição analítica, visto que a razão realizada se confunde com o Estado de direito, assim como o Estado de fato é o devir da razão (Deleuze; Guattari, 1997, p. 44-45).

Essa é a troca que leva ao senso comum no qual o Estado se torna a única organização racional que pode administrar e controlar os ímpetos selvagens dos seres humanos, ao mesmo tempo em que impede, que evita que a sociedade destrua a bondade intrínseca aos seres humanos, como proporiam dedicadas análises hobbesianas e rousseaunianas. Estado que se torna consenso absoluto, sendo então, de acordo com Deleuze e Guattari, a imagem do pensamento única pela qual toda a discussão política é atravessada, que se funda em uma totalidade englobante, e que aspira à universalidade.

De acordo com Jacques Rancière (1996), para compreender a atividade política, é necessário que se entenda a sua diferença em relação à polícia. Ele realiza um intenso debate sobre o estatuto da política e sobre a forma como, desde o pensamento político de Platão e Aristóteles, a política está relacionada muito mais à noção de contagem das partes da comunidade, do que necessariamente aos vínculos dos indivíduos entre si e a pólis. Para esclarecer melhor, é preciso citar parte do episódio “processo dos quinze”, trazido por Rancière, em relação ao diálogo ocorrido por causa do processo movido contra o operário revolucionário Auguste Blanqui, em 1832:

Instado pelo presidente do tribunal a declinar sua profissão, ele responde simplesmente: "proletário". A essa resposta, o presidente objeta de pronto: “Isso não é profissão", para logo o acusado replicar: "É a profissão de trinta milhões de franceses que vivem de seu trabalho e que são privados de seus direitos políticos". 0 que faz o presidente permitir que o escrivão anote essa nova "profissão" (Rancière, 1996, p. 49).

Para Rancière, as duas réplicas presentes nesse diálogo podem resumir o conflito que existe entre as noções de política e de polícia. A palavra profissão, para a lógica policial, significa um ofício ou uma atividade de um corpo devidamente situada em 
um lugar e em uma função. Nesse caso, o proletário é um trabalhador braçal que vive em uma situação miserável. Mas, para Blanqui, ser proletário, naquele momento, não significa estar em nenhuma das classificações instituídas pela lógica estatal policial, mas, sim, remete a uma multiplicidade de indivíduos que não podem ser contados, de acordo com um entendimento de grupos sociais, previamente estabelecidos, no conjunto da comunidade.

É preciso esclarecer um pouco mais o que Rancière sugere como a diferença entre os conceitos de política e polícia. Ele busca, nos fundadores do pensamento político ou da filosofia política da Grécia Antiga, a ideia na qual uma pólis organizada pela ideia de bem é estruturada de acordo com o valor de cada uma das comunidades contabilizadas por ela. Se há uma diferenciação enorme entre as classes de acordo com suas posses e poderes judiciários, intenta-se tornar iguais os poderes de fala e participação de cada um desses grupos. De acordo com Rancière, a crítica que pensadores políticos fazem ao poder dado aos escravos recém-libertos, deixando-os participar das discussões públicas na demos ateniense, é um escândalo que somente poderia levar às práticas demagógicas nas quais alguns nobres se aproximariam mais do povo somente para ter vantagens nas tomadas de decisões.

O ódio por essa democracia, nas obras de pensadores como Platão, se dá no fato que o tal povo que não tem parcela nas riquezas da pólis, devido aos danos causados pelas classes superiores, é membro participante dos debates públicos, tendo o mesmo estatuto político dos membros dos outros grupos mais abastados e, por ser a grande massa da população ateniense e defender suas causas, causa um retorno do dano à pólis. É um erro de cálculo que "arruína, em cadeia, toda a dedução das partes e títulos que constituem a polis" (Rancière, 1996, p. 25).

Rancière questiona se essa troca da aritmética das igualdades mercantis e judiciárias pela geometria do bem comum não passaria de uma construção ideal de uma sociedade onde não haveria mais uma luta de classes. Afirma ele que foram os pensadores antigos - especialmente Heródoto, ao falar sobre os escravos dos citas que sugeriram o fato de somente haver política quando existe a participação de uma "parcela dos sem-parcela", ou um partido dos pobres. Fora disso, existe apenas ou a tirania, ou o caos da revolta.

Por sua vez, se por um lado, a existência do partido dos pobres - e dos pobres em si - expõe o dano da pólis, a sua ausência de princípios da comunidade, e a ausência de qualidade onde, teoricamente, deveria haver uma qualidade em comum, fazendo 
com que a política esteja sempre presente, por outro lado, os partidos dos ricos - e de acordo com Rancière, o discurso existe até hoje - irão afirmar que não existe a parcela dos sem-parcela e sim, chefes e subordinados, peritos e ignorantes, elites e multidões, maiorias e minorias sociais, diferentes categorias sociais, grupos de interesse, etc., e que a política se resumiria ao litígio existente entre essas classes.

Para Rancière, o fundamento da política - retomando a disputa célebre entre socráticos e sofistas - não é nem natureza e muito menos convenção, mas, justamente, a falta de fundamento, já que nenhuma lei divina ordena as sociedades humanas. E existe a política, pois a ordem natural criada por senhores, reis e pastores para que exista um falso princípio à comunidade - o que Rancière resgata como arkhé - é interrompida pela "liberdade que vem atualizar a igualdade última na qual assenta toda ordem social" que havia sido estabelecida pela natureza social, por intermédio da majestade, da divindade, dos exércitos e das gestões de interesses:

Só existe política quando essas maquinarias são interrompidas pelo efeito de uma pressuposição que lhes é totalmente estranha e sem a qual no entanto, em última instância, nenhuma delas poderia funcionar: a pressuposição da igualdade de qualquer pessoa com qualquer pessoa, ou seja, em definitivo, a paradoxal efetividade da pura contingência de toda ordem (Rancière, 1996, p. 31).

Em outras palavras, para Rancière (1996, p.33), a política somente existe quando ela rompe a ordem social estabelecida sob o regime de igualdade de participação nas decisões da comunidade no momento em que um grupo que não existia, ou parecia não saber a linguagem estabelecida nas discussões democráticas, abre a boca e consegue falar a mesma língua dos outros grupos então estabelecidos. "É a introdução do incomensurável no meio dos corpos falantes”, que destrói completamente todo o projeto político de distribuição das partes que igualmente definem o futuro em comum, as quais até então pareciam naturalmente estabelecidas e estavam muito bem ordenadas dentro dos grupos representados na comunidade.

Esse incomensurável rompe completamente toda a compreensão da política e expõe algo que, de toda forma, havia sido combatido pelo ideal político de composição de uma sociedade, que é o estabelecimento da diferença em uma ordem que, até então, havia se pautado - ou tentado se pautar - pela noção na qual só havia a igualdade na 
comunidade política, já que todas as partes da sociedade eram devidamente conhecidas, já que falavam a mesma língua, fossem as classes mais abastadas, fosse o povo.

Rancière busca nos textos políticos de Ballanche ${ }^{2}$ sobre a sucessão dos plebeus romanos no Aventino por volta de 450 a.C. e na ascensão ao poder do cônsul Menênio Agripa e dos patrícios, uma situação clara onde está exposta a noção que desenvolve sobre política. Os plebeus não falavam a linguagem dos patrícios que, portanto, se recusavam a dialogar. Por isso, não poderiam participar dos debates públicos, pois não eram considerados como parte da comunidade política. Diferentemente do povo grego, considerado como parcela dos sem-parcela - mas poderiam participar das discussões da pólis, pois havia a mesma linguagem - os plebeus, por apenas emitirem “mugidos e ruídos”, jamais poderiam reivindicar qualquer espaço na República Romana - então em ascensão.

Ao invés de se levantarem em armas ou se entrincheirarem esperando o conflito armado, os plebeus resolveram transgredir a ordem política da cidade, ao exercer a fala, reivindicar um nome e transformar-se de mortais em homens. Pronto, a política tinha sido exercida, não porque, de acordo com Rancière, haviam sido expostos os interesses em comum, mas por terem colocado em comum os enfrentamentos de dois mundos alojados em um só. A agregação dos grupos humanos, agora falantes ao corpo da comunidade, e o consequente consentimento do estar-junto coletivo, mais a reorganização, a recristalização e a legitimação da ordem hierárquica, que comumente era chamada de política - pois ouve todos os setores de uma sociedade - passaram a ser definidos por Rancière como polícia.

Essa polícia, que não deve ser confundida como somente o aparelho de Estado, é uma configuração do sensível, ou seja, a definição da ordem dos corpos que estabelece divisões entre modos de fazer, ser e dizer. É uma ordem do sensível, pois está direcionada ao que é visível e dizível, fazendo com que uma ação seja visível ou não, e uma palavra seja entendida como discurso, e a outra não: “A polícia não é tanto uma 'disciplinarização' dos corpos quanto uma regra de seu aparecer, uma configuração das ocupações e das propriedades dos espaços em que essas ocupações são distribuídas" (Rancière, 1996, grifo do autor, p. 42).

A polícia é uma atividade que difere conforme o período e o contexto, podendo haver uma polícia mais brutal ou mais doce e amável, como é o caso das constantes pesquisas de opinião pública, e

2. Teórico político contrarrevolucionário francês que, de acordo com Rancière (1996, p. 36), tentou estabelecer um vínculo entre a política clássica e a moderna em um conjunto de artigos publicados em 1830, chamado “Fórmula geral da história de todos os povos aplicada a história do povo romano". 
sua consequente divulgação, por exemplo, sobre a questão ambiental, e a importância de resolver os problemas relativos à água, ao aquecimento global e à destruição da Amazônia. Dificilmente se contesta a legitimidade desses problemas, e todas as discussões, consideradas pelos meios midiáticos como políticas, são tentativas de buscar soluções para essas questões.

A política procura desfazer essa ordem policial, tornando em discurso aquilo que parecia somente ser barulho, e deixando a olhos vistos o que não era tido como existente. Qualquer coisa pode vir a ser política, e não o que já é necessariamente política. Um movimento é político quando exige e exerce a diferença, expondo-a e mantendo-a viva perante o consenso até então estabelecido.

\section{Por ecologias e educações ambientais políticas...}

Se o governo e o Estado - ou para Deleuze (2006), a forma-Estado - precisaram se autolimitar para poder manter a governamentalidade em uma sociedade povoada de seres econômicos, e, para isso, precisaram criar a sociedade civil, para responder a uma reivindicação educacional popular e múltipla que é a educação ambiental, acabam usando da mesma tática e do mesmo conceito para atender aos anseios dos educadores ambientais e, consequentemente, usá-la para uma prática policial. Existe um movimento que é, ao mesmo tempo, local e, para utilizar a linguagem de Foucault (2008), “transnacional”, que escapa às relações de poder, que ele chama de "realidade de transação", que nem sempre existiu, que uma hora pode ser chamado de sociedade civil, em outro momento de loucura, e talvez, cabendo aqui, de ecologia. Mas o que interessa é que são realidades que podem ser identificáveis, classificáveis e colocadas nos devidos lugares, onde não mais destruirão as noções instituídas e nem, consequentemente, a ordem policial estabelecida.

E é nesse sentido que a educação ambiental pode ser compreendida a partir da perspectiva política que Rancière faz em sua obra, principalmente no que diz respeito ao conceito de constituição policial. A criação de leis para a implantação de uma política de educação ambiental regulamenta e normatiza um conjunto de pensamentos em práticas que, até então, pareciam inconstantes, desorganizadas e não efetivas. Se, por um lado, pode representar uma conquista no que diz respeito à resolução dos problemas ambientais, por meio da implementação de práticas pedagógicas que levem em consideração a situação ambiental global e local, por outro lado, traz uma série de riscos que podem, como alertava Castoriadis (2006), dar origem a um fascismo 
ambiental, o qual, ao invés de promover as transformações e as mudanças reivindicadas pelos movimentos ambientalistas, pode impedir qualquer participação política das mais diversas perspectivas que compõem o campo da educação ambiental.

O movimento ecológico e os educadores ambientais, ao trazerem à tona nas sociedades ocidentais a questão ambiental e o risco de extinção dos seres humanos e do planeta, exigiram dos poderes constituídos uma imediata resolução dessas questões; seja pela adoção das políticas de proteção ao ambiente, seja pela extinção das instituições estatais e privadas, causadoras da destruição. Desfizeram quase completamente, em um primeiro momento, tudo o que era o padrão para o estabelecimento de uma sociedade justa e saudável, ao introduzir o viés ambiental. O que era, até então, aparentemente inexistente ou invisível, se fez ver de maneira potente e cada vez mais inquestionável. A ecologia, como preocupação humana, não existia, assim como o ecologista como um agente político. Foi esse nascimento do movimento ecológico, e a educação ambiental em sua esteira, que fizeram com que a política surgisse:

A política é assunto de sujeitos, ou melhor, de modos de subjetivação. Por subjetivação, vamos entender a produção, por uma série de atos, de uma instância e de uma capacidade de enunciação que não eram identificáveis num campo de experiência dado, cuja identificação portanto caminha a par com a reconfiguração do campo da experiência... (Rancière, 1996, p. 47).

O ecologista, o movimento ecológico e o educador ambiental, como agentes políticos, foram capazes de desmembrar a configuração identitária da sociedade dos anos 1960, e buscaram fazer da ecologia uma temática tão importante quanto a economia e a cultura nas questões contemporâneas. Esses agentes políticos, assim como o proletário de Blanqui no século XIX, não eram nem profissionais, nem agentes políticos, nem representantes de setores sociais. Mas, a partir do momento em que tornaram a ecologia um tema da economia, da cultura, da política, da sociedade, da educação e da ciência, todo um esforço foi estabelecido para dar-lhe uma constituição policial. A ecologia política passou a ser "ecologia polícia".

A partir disso, não sobrou mais nada do potencial político que outrora, de maneira intensa e retumbante, havia feito com que o mundo repensasse suas práticas e seu futuro? Para a ecologia e a educação ambiental o que sobrou foi somente essa atividade policial? 


\section{... que sejam ecologias e educações ambientais do dissenso?}

É necessário esclarecer que, apesar do embate existente entre a lógica policial dos atores de poder e as subjetivações políticas presentes nos enunciados até então inexistentes, não é possível compreender a assimilação do discurso ecológico e da educação como um embate entre o bem e o mal em uma perspectiva messiânica, ou uma disputa de classes dialética de caráter metanarrativo.

Os riscos de afirmar que somente uma análise dual da realidade pode dar conta dos fundamentos para a teoria/prática da educação ambiental podem debandar para um fascismo epistemológico e metodológico, típico das mais fanáticas militâncias extremistas que visam ao poder do Estado, sejam elas nacionalistas de direita, ou stalinistas/maoistas de esquerda. Afirmar que uma única perspectiva teórico-metodológica pode dar conta de compreender toda a multiplicidade envolvida nas relações humanas desconsidera a pluralidade que construiu a educação ambiental no Brasil e no mundo. Mais do que afirmar sobre uma ecologia política, pode ser mais apropriado se falar em muitas e heterogêneas ecologias políticas.

Algumas das perspectivas no debate entre educação e ambiente hoje em ascensão e alheias à tomada do poder instituído como modo de resolução das questões ambientais - como as filosofias da diferença, os estudos culturais e os anarquismos contemporâneos, metodológicos e ontológicos - discutem a educação ambiental e contestam os usos feitos dela pelas esferas de poder estatal e privado. Elas não contestam somente o poder que usa a educação ambiental para se manter estabelecido, mas também as perspectivas que a usam para chegar ao poder e estabelecer regimes despóticos tão ou mais fascistas que os regimes vigentes, usando a educação ambiental como uma de suas ferramentas privilegiadas para tal.

Quando as pesquisas em educação ambiental recorrem aos Estudos Culturais³, elas não estão preocupadas em fazer uma análise que abarque uma totalidade das questões ambientais por meio das narrativas, do estudo dos cotidianos, das imagens, das artes visuais e do cinema, mas sim, em saber quais as contribuições que essas esferas dão ao conjunto de campos que compõe o multiverso chamado educação ambiental.

Assim como a educação ambiental, ao se articular com o anarquismo e as filoso-

3. As relações entre a educação ambiental e os Estudos Culturais são amplamente debatidas no trabalho de Guimarães, Krelling e Barcelos (2010).

4. Sobre as relações entre educação, anarquismo e filosofias da diferença, ver Gallo (2007). fias da diferença ${ }^{4}$, não está determinada a desvendar as grandes questões dicotomizadoras entre sociedade e natureza, Estado e sociedade civil ou capitalismo e liberdade, muito menos pretende 
centralizar em um único fenômeno - seja ele a educação, a cultura, o ambiente, o trabalho, o capital, entre outros - toda a multiplicidade do fazer humano, o significado da nossa existência no planeta e sua relação com as questões de educação e meio ambiente. Ela busca, nesse sentido, tanto compreender a capilaridade das ações promovidas pelas ferramentas e dispositivos de poder e as múltiplas resistências que essas ações envolvem quanto promover processos educativos que permitam potencialidades coletivas, linhas de desejo autônomas e promoção de novas possibilidades de ação política que estejam atreladas aos cuidados que o meio ambiente e os outros seres vivos "exigem" dos seres humanos.

É um agir nas brechas, nas fendas, por trincheiras labirínticas de avanço e ultrapassagem, de fuga e escape, nas quais essas perspectivas buscam agir, pois sabem que não podem, sozinhas, estabelecer verdades supremas e únicas, incontestáveis, sobre a educação ambiental e sobre uma polícia normatizadora e controladora de ações ecológicas. Muito menos, essas perspectivas lutam por reconhecimento, um lugar ao sol ou por terem suas verdades inseridas em verdades maiores, peças de uma verdade unívoca para a qual somente contribuem.

Essas perspectivas querem se manter políticas, vivas, inventivas e antropofágicas. Lutam para evitar que sejam destruídas por um exercício de cristalização e identificação que thes retiraria qualquer possibilidade e potencialidade de estabelecer diferenças e manter a força de sua ação política. Uma ação política que, de acordo com Rancière (1996) está sempre atrelada - de maneiras multiplamente inversas e contrárias - à lógica policial presente em um determinado tempo e espaço.

Nesse caso, talvez seja possível encontrar a força política da educação ambiental no momento em que ela busque em espaços onde seja improvável a existência de qualquer laço com a ecologia, os aspectos que lhe permitam manter sua perspectiva aberta e nômade. E não é que a ecologia não esteja presente nesses espaços, mas é pelo fato de eles, até então, serem incompreensíveis ao entendimento da educação ambiental. 0 esforço que ela faz, quando se encontra com os Estudos Culturais, as Filosofias da Diferença e os Anarquismos contemporâneos, é justamente buscar no que Guattari e Negri (1999) sugeriam como novos espaços da liberdade, algumas verdades nômades e múltiplas que, até então, não conseguia compreender, justamente por não entender a linguagem desses espaços.

Espaços, por exemplo, como o grafite e a pichação $0^{5}$ ou aquele criado pelas bandas underground po educacional, ver os trabalhos de Coelho $(2009,2012)$. 
de death metal, thrash metal e grindcore ${ }^{6}$ - entre outros subestilos surgidos nos anos 1980 a partir do heavy metal e punk tradicionais - as quais, em diversas músicas e capas de EPs, LPs, CDs, coletâneas, fanzines, camisetas e patches ${ }^{7}$, abordam tanto os temas clássicos do discurso ecológico - como poluição, destruição de áreas verdes, proteção aos animais, antibelicismo e a questão energético- nuclear, até algumas questões como feminismo, aborto, internacionalismo, homofobia, mobilidade urbana, antifascismo, entre outros, as quais, apesar do equívoco de ser colocada em segundo plano dentro das discussões ecológicos, de acordo com Guattari (1991), são inerentes e também primordiais a esse debate.

Quando as educações ambientais se encontram com discursos, manifestações e fenômenos que parecem, ao lugar comum e senso comum da educação ambiental, não ter nenhum elo com a temática ecológica e nenhuma reivindicação de tomada de poder governamental instituído ou pretensões corporativas financeiras, elas reivindicam a sua capacidade de fazer política, pois entendem que, somente assim, podem se manter existentes e pertinentes.

Ao buscar uma fuga, um escape ou uma ultrapassagem da ordem instituída para, de acordo com Rancière (1996) se relacionar com as parcelas dos incontados, ou desclassificados, desqualificados, não humanos ou não políticos, entre outras adjetivações, promovendo o caos de átomos ovacionado por Nietzsche, ou a autonomia sugerida por Guattari, as educações ambientais tanto manifestam um desejo de afetar os espaços educativos - formais ou informais, constituídos ou constituintes - com o propósito de potencializar novas relações dos humanos com os ambientes que os cercam, inventando novas ecologias, quanto se mantêm vivas, ativas, múltiplas, singulares e singularizantes, constantemente nômades.

6. Para um melhor entendimento dos referidos estilos e das principais bandas, ver os trabalhos de Christe (2010), Mudrian (2009) e O'Hara (2005)

4. Pequenos pedaços de tecidos, ornamentados com os desenhos dos logotipos das bandas, capas de discos ou mensagens políticas. 


\section{Referências bibliográficas}

ALVES, Karina Mirian da Cruz Valença. Formação discursiva da plenitude em educação: uma arqueogenealogia das novas sensibilidades eco-pedagógicas. In: REUNIÃO ANUAL DA ASSOCIAÇÃO BRASILEIRA DE EDUCAÇÃO - ANPED, 33., 2010, Caxambu MG.

AZEREDO, Verônica Pacheco de Oliveira. Nietzsche: a grande saúde e o sentido trágico da vida. Cadernos Nietzsche. São Paulo, v. 28, p. 249-261, 2011. Disponível em: http://www.cadernosnietzsche.unifesp.br/pt/home/item/164-nietzsche-agrande-sa\%C3\%BAde-e-o-sentido-tr\%C3\%A1gico-da-vida. Acesso em: 25 fev. 2013.

BRASIL. Decreto n 4.281, de 25 de junho de 2002. Regulamenta a Lei n-9 9.795, de 27 de abril de 1999, que institui a Política Nacional de Educação Ambiental, e dá outras providências. Diário Oficial [da República Federativa do Brasil], Brasília, DF, v. 139, n. 121, 26 jun. 2002, seção 1, p. 13.

BRASIL. Lei no 9.795, de 27 de abril de 1999. Dispõe sobre a educação ambiental, institui a Política Nacional de Educação Ambiental e dá outras providências. Diário Oficial [da República Federativa do Brasil], Brasília, DF, v. 137, n. 79, 28 abr. 1999, seção 1, p. 1-3.

CASTORIADIS, Cornelius. Uma sociedade à deriva: entrevistas e debates, 1974-1997. Tradução de Claudia Berliner. Aparecida, SP: Idéias e Letras, 2006.

CHRISTE, Ian. Heavy Metal: a história completa. Tradução de Milena Durante e Augusto Zantoz. São Paulo: Arx; Saraiva, 2010.

COELHO, Gustavo. Pixação e metrópole: potências e belezas de jovens inúteis. In: ENCONTRO NACIONAL DE PRÁTICAS DE ENSINO, 16., 2012, Campinas. Políticas educacionais e impactos na escola e na sala de aula. Araraquara/SP: Junqueira\&Marin Editores, 2012.

COELHO, Gustavo. Pixações na metrópole: uma pedagogia fora da lei. In: REUNIÃO ANUAL DA ANPED, 32., 2009, Caxambu. Sociedade, cultura e educação: novas regulações?, 2009.

CORRÊA, Guilherme Carlos. Ecologia e educação na sociedade de controle. In: PREVE, Ana Maria Hoepers et al. (Org.). Ecologias inventivas: conversas sobre educação. Santa Cruz do Sul: Edunisc, 2012.

DELEUZE, Gilles. Foucault. Tradução de Claudia Sant’Anna Martins. São Paulo: Brasiliense, 2006.

DELEUZE, Gilles; GUATTARI, Félix. Mil platôs: capitalismo e esquizofrenia. Tradução de Peter Pál Pelbart e Janice Caiafa. v.5. São Paulo: Editora 34, 1997. 
FOUCAULT, Michel. O nascimento da biopolítica: curso no College de France (19781979). Tradução de Eduardo Brandão. São Paulo: Martins Fontes, 2008.

GALLO, Sílvio. Pedagogia libertária: anarquistas, anarquismos e educação. São Paulo: Imaginário; Editora da Universidade Federal do Amazonas, 2007.

GODOY, Ana. A menor das ecologias. São Paulo: Edusp, 2008.

GUATTARI, Félix. As três ecologias. Tradução de Maria Cristina F. Bittencourt. Campinas: Papirus, 1991.

GUATTARI, Félix; NEGRI, Antonio. Las verdades nomadas \& General Intellect, poder constituyente, comunismo. Tradução de Carlos Prieto Del Campo e Mario Domingues Sánchez. Madrid: Ediciones Akal, 1999.

GUATTARI, Félix; ROLNIK, Suely. Micropolítica: cartografias do desejo. 10. ed. Rio de Janeiro: Vozes, 2010.

GUIMARÃES, Leandro Belinaso. Fulgurações: pelos rastros da educação ambiental. In: PREVE, Ana Maria; CORREA, Guilherme. Ambientes da ecologia: perspectivas em política e educação. Santa Maria: Editora da UFSM, 2007.

GUIMARÃES, Leandro Belinaso; KRELLING, Aline; BARCELOS, Valdo (Org.). Tecendo educação ambiental na arena cultural. Petrópolis: DP\&Alli, 2010.

LAROSSA, Jorge. Nietzsche e a educação. Tradução de Semíramis Gorini da Veiga. Belo Horizonte: Autêntica, 2005.

MUDRIAN, Albert. Eligiendo muerte: la improbable historia del Death Metal y Grindcore. Tradução de Carlos San Román C. NY: Bazillion Points, 2009.

NIETZSCHE, Friedrich. A gaia ciência. Tradução de Márcio Pugliesi, Edson Bini e Norberto de Paula Lima. 3. ed. São Paulo: Hemus, 2002.

NIETZSCHE, Friedrich. Aurora: reflexões sobre os conceitos morais. Tradução, notas e posfácio: Paulo Cesar de Souza. São Paulo: Companhia das Letras, 2004.

NIETZSCHE, Friedrich. Consideração Intempestiva: Schopenhauer educador. Escritos sobre educação. Tradução, apresentação e notas de Noéli Correia de Melo Sobrinho. 6. ed. Rio de Janeiro: PUC-Rio; São Paulo: Loyola, 2012.

NIETZSCHE, Friedrich. Escritos sobre Política. Tradução, apresentação e notas de Noéli Correia de Melo Sobrinho. Rio de Janeiro: PUC-Rio; São Paulo: Loyola, 2007.

O’HARA, Craig. A filosofia do punk: mais do que barulho. Tradução de Paulo Gonçalvez. São Paulo: Radical Livros, 2005.

PASSETI, Edson. Ecopolítica e controle por elites. In: PREVE, Ana Maria; CORREA, Guilherme. Ambientes da ecologia: perspectivas em política e educação. Santa Maria: Editora da UFSM, 2007. 
PREVE, Ana Maria Hoepers et al. (Org.). Ecologias inventivas: conversas sobre educação. Santa Cruz do Sul: Edunisc, 2012.

PREVE, Ana Maria Hoepers; CORREA, Guilherme. Ambientes da ecologia: perspectivas em política e educação. Santa Maria: Editora da UFSM, 2007.

RANCIÈRE, Jacques. O desentendimento - política e filosofia. Tradução de Angela Leite Lopes. São Paulo: Editora 34, 1996.

REIGOTA, Marcos. Cidadania e educação ambiental. Psicologia e Sociedade. Porto Alegre, v. 20, n. esp., p. 61-69, 2008.

Submetido à avaliação em 29 de agosto de 2013.

Aprovado para publicação em21 de novembro de 2013. 